\title{
A neuro-data envelopment analysis approach for optimization of uncorrelated multiple response problems with smaller the better type controllable factors
}

\author{
Mahdi Bashiri ${ }^{1 *}$, Amir Farshbaf-Geranmayeh ${ }^{2}$ and Hamed Mogouie ${ }^{1}$
}

\begin{abstract}
In this paper, a new method is proposed to optimize a multi-response optimization problem based on the Taguchi method for the processes where controllable factors are the smaller-the-better (STB)-type variables and the analyzer desires to find an optimal solution with smaller amount of controllable factors. In such processes, the overall output quality of the product should be maximized while the usage of the process inputs, the controllable factors, should be minimized. Since all possible combinations of factors' levels, are not considered in the Taguchi method, the response values of the possible unpracticed treatments are estimated using the artificial neural network (ANN). The neural network is tuned by the central composite design (CCD) and the genetic algorithm (GA). Then data envelopment analysis (DEA) is applied for determining the efficiency of each treatment. Although the important issue for implementation of DEA is its philosophy, which is maximization of outputs versus minimization of inputs, this important issue has been neglected in previous similar studies in multi-response problems. Finally, the most efficient treatment is determined using the maximin weight model approach. The performance of the proposed method is verified in a plastic molding process. Moreover a sensitivity analysis has been done by an efficiency estimator neural network. The results show efficiency of the proposed approach.
\end{abstract}

Keywords: Multiple response optimization; Artificial neural networks; Data envelopment analysis; Smaller-the-bettertype controllable factors

\section{Introduction}

Today's competitive environment impels companies to improve the quality of their products proactively, so the design of experiments (DOEs) can be one of the most efficient methods for this purpose. The experimental design helps us find the effects of the controllable and nuisance factors on one or more responses. Finding the combination of controllable factor levels, namely treatment, which leads to the most appropriate process outputs is one of the common challenges in quality engineering researches.

The Taguchi method is a common strategy in the robust design and involves designing experiments with the use of orthogonal arrays for finding the treatment

\footnotetext{
* Correspondence: bashiri@shahed.ac.ir

'Department of industrial Engineering, Faculty of Engineering, Shahed University, Khalij Fars Highway, Tehran P.O. BOX: 3319118651, Iran Full list of author information is available at the end of the article
}

which optimizes a given performance measure, typically a signal-to-noise (SN) ratio.

The Taguchi method was initially proposed for single response problems (Taguchi and Chowdhury 2000; Maghsoodloo et al. 2004; Robinson et al. 2004; Zang et al. 2005). However, in real industrial problems, there are more than one responses and their simultaneous optimization is of the interest.

Multiple-response optimization (MRO) problems have been studied by several researchers. Existing methods in this field are classified into three basic categories by Ortiz et al. (2004). The performance of each category depends on the complexity of the problem. In the first category, overlying contour plots of each response is applied for finding the space where each response satisfies its specification limits. Myers and Montgomery (2002) expressed that this method is applicable only in the 
situations where the numbers of controllable factors are very few. In the second category, the most important response for the decision maker $(D M)$ is used as the main objective and the rest of responses are considered as constraints. However the approaches in this category do not conform to the basic idea of multiple-response optimization which is the simultaneous optimization of all responses.

The third category, which contains a major proportion of studies in MRO, consists of three main steps to find the optimal treatment. In the first step, a model for describing the relation between controllable factors and responses is built. In the second step, an aggregation approach of responses is applied. Finally, in the third step, an optimization method is used for optimizing the single response which is obtained from the last step. In the mentioned categories, Ordinary Least Square (OLS) is one of the common methods for building the model of relation between controllable factors and responses (first step). Although in some researches such as Bashiri and Moslemi (2013), robust optimization methods are applied; one of the major shortcomings of the studies in this category is that when the mean square error (MSE) of the regression model is a high value, the ability of the model to describe the relationship of the response variables and the controllable factors would be poor (Erzurumlu and Oktem 2007). For overcoming this problem, ANN can be used as a proper substitute method for response estimation. Some authors have compared response surface and regression models with ANN in model building and the preciseness of ANN has been verified in their results (Tsao 2008; Desai et al. 2008; Namvar-Asl et al. 2008; Gauri and Pal 2010).

Furthermore, Niaki and Hoseinzade (2013) used ANN for forecasting $\mathrm{S} \& \mathrm{P}$ indices where the experimental design was used for tuning the parameters of the neural network.

A numerous number of researchers studied about using artificial neural networks for solving MRO problems. The summary of existing approaches is illustrated in Figure 1, where the studies are classified according to the techniques each of them has used.

In MRO problems, different multi-criteria decision making methods have been used to determine the optimum treatment (for a review see Amiri et al. (2012)). Data envelopment analysis (DEA) is one of these techniques which have been used in several researches. Caporaletti et al. (1999) proposed a pure input DEA model for the nominal-the-best (NTB)-type responses using $\left(\bar{y}_{i j}-y_{i}\right)^{2}$ and $S_{i j}^{2}$ as input variable. In this study, just the experimented treatments have been evaluated. Liao and Chen (2002) proposed an input-oriented basic DEA ratio known as the Charnes, Cooper and Rhodes (CCR) model introduced by Charnes et al. (1978) that uses the normalized mean responses as input variables when the responses are the NTB or the smaller-thebetter (STB) type; also, Goel et al. (2007) proposed a new method in multiple-response optimization using the Pareto optimal solution.

In the model of Liao and Chen (2002), when the responses are LTB type, the normalized mean responses are considered as the output variable. Herein again, only the real experimented treatments and their corresponding responses are considered. Liao (Goel et al. 2007) also used a back propagation (BP) neural network (trained with the data of the actual treatments) to estimate the $\mathrm{SN}$ ratio of responses for all treatments and then efficient treatments are determined by the CCR DEA model, considering normalized SN ratio as outputs.

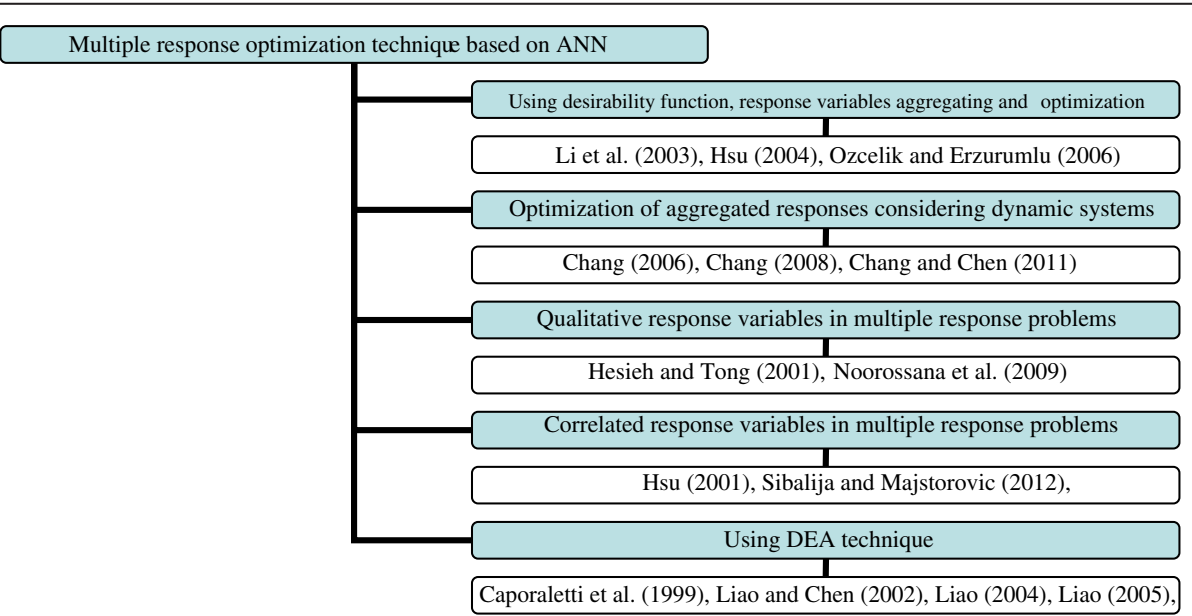

Figure 1 A taxonomy of methods for multiple-response optimizations using ANN (Li et al. 2003, Hsu 2004, Ozcelik and Erzurumlu 2006, Chang 2006, Chang 2008, Chang and Chen 2011, Hesieh and Tong 2001, Noorossama et al. 2009, Hsu 2001, Sibalija and Majstorovic 2012, Caporaletti et al. 1999, Liao and Chen 2002, Liao 2004, and Liao 2005). 
In Liao (Goel et al. 2007), the same DEA model is used but all possible treatments are estimated using a BP neural network. In their proposed approach, the most treatment is not selected.

Gutierrez and Lozano (2010) used a similar approach to find the efficient treatment and then sieve the most efficient among the efficient ones.

In the mentioned literature of the studies which have used DEA for the determination of the optimum treatment, only the response variables have been focused on, while the main philosophy of DEA is maximization of the overall process outputs versus the minimization of the total consumed inputs.

Many real world processes can be exampled where the controllable factors are STB type. For instance, in a plastic molding process, one of the factors is the barrel temperature, of which the less value is more preferred. The higher temperature impels more electricity consumption and equivalently more costs. By considering other similar STB controllable factors as inputs and the $\mathrm{SN}$ ratio of response variables as the outputs of the process, the main philosophy of DEA would be realized. The final results of DEA for such a problem would assure us that the most appropriate quality of the process is obtained by the least consumption of input variables.

In this paper, a new approach is developed based on the neural network and data envelopment analysis where controllable factors are the STB type and the responses are uncorrelated. Besides, it is. In this method, the ANN is used to estimate the response values for unpracticed treatments in a way that the multiple responses are obtained simultaneously. In this paper, the used neural network is tuned by the method proposed by Bashiri and Geranmayeh (2011). In their method, the Central Composite Design (CCD) and the Genetic Algorithm (GA) have been used to tune and determine the optimum parameters of the neural network, specifically the number of the layers and the number of neurons in each layer.

After tuning the ANN, the unpracticed treatments with smaller intervals of factor levels are generated and their corresponding responses are estimated by the ANN.

In the next step, by using DEA, the efficiency value of each treatment is computed. Finally, the most efficient treatment is determined using the maximin weight model approach.

The remainder of the article is organized as follows: in the next section, the steps of the proposed approach are described. In section 3 , the proposed method is implemented in a real world case study and the steps of the proposed method are explained thoroughly. Finally, section 4 summarizes and draws the conclusion.

\section{Proposed approach}

This section describes the proposed methodology which is illustrated in Figure 2.

\section{Experimentation phase}

In the first step of any design of experiment problems, the responses and their descriptions such as their types

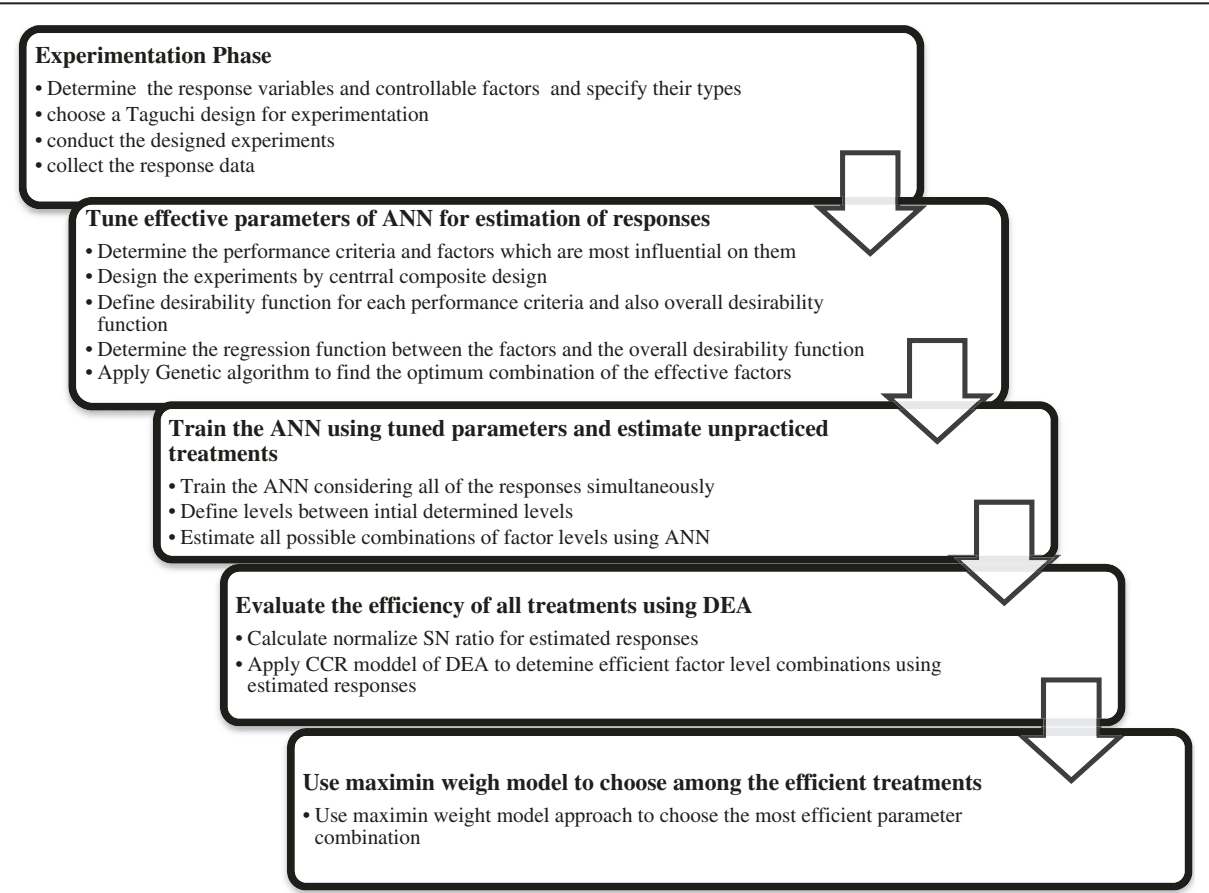

Figure 2 Flow chart of the proposed approach. 
should be determined. Also, the controllable factors and their corresponding levels should be specified according to the technical knowledge of the process and the execution limitations. By knowing the required information of responses and the controllable factors, a Taguchi design is chosen and conducted and the response data are collected. The outputs of this step are the $\mathrm{SN}$ ratio values computed for each response in each treatment. Note that the responses are assumed to be uncorrelated.

\section{Tune-effective parameters of ANN for estimation of responses}

For obtaining desirable results by using Artificial Neural Networks, tuning the parameters of ANN seems to be necessary. For example, the number of layers and the number of neurons in each layer are effective parameters in the performance of neural networks. Some authors have used the design of experiments (DOE) for determining the best combination of effective parameters of ANN. Khaw et al. (1995) used the Taguchi method as well as two simulated data collections to determine the effective parameters of ANN, which caused to increase the velocity and convergence of the Back Propagation (BP) algorithm. Also, other similar researches have been proposed in this field, such as the studies of Kim and Yum (2004), Sukthomya and Tannock (2005), Tortum et al. (2007), Packianather et al. (2000), and Peterson et al. (1995). Bashiri and Geranmayeh (2011) proposed a method for tuning the parameters of the artificial neural network based on CCD and genetic algorithm. Because of the accuracy and generalization capability of this approach, in this study, we applied this method for tuning the parameters of the neural network with some necessary changes in determining the neural network's performance criteria. The condition of the problem determines the proper performance criteria of the neural network.

For training ANNs, the data are divided into three subsets: training, validation, and testing sets. In this study, root mean square error (RMSE) of the test and validation data are considered as ANN's performance criteria in estimation of responses in the multiple response optimization problem. In this step, the optimum number of hidden layers and the number of neurons in hidden layers are obtained.

\section{Train ANN using tuned parameters and estimate the unpracticed treatments}

In the previous step, optimal parameters of ANN for this problem are obtained. So, the neural network is ready to be trained and estimate the response values of unpracticed treatments.

After the training phase, neural network builds a model and can estimate other treatments which are not experimented. Since the trained neural network's response estimation is not affected by the number of factor levels, new levels are defined between the initial factor levels. This procedure improves the accuracy of the solution.

In mentioned studies, the neural network is used to estimate the $\mathrm{SN}$ ratio or the mean square deviation (MSD) of responses. But in the cases where a nuisance factor exists, the effect of the nuisance factor is neglected and the nuisance factor is treated as a replicate. In this study, for solving this problem, ANN is applied for estimating responses, not the $\mathrm{SN}$ ratios or MSDs of responses. As Chang (Ozcelik and Erzurumlu 2006) applied ANN in dynamic multiple response experiments, factors and nuisance factors are considered as inputs for training of the neural network.

\section{Evaluate the efficiency of all treatments using DEA}

DEA is used to compute the relative efficiency of a group of competing decision-making units (DMUs), while there are several inputs and outputs for each DMU (Tbanassoulis 2001). The relative efficiency is the ratio of the weighted sum of outputs to the weighted sum of inputs.

Thus, if a DMU wants to have an upper efficiency, the input data must be minimized and the output data must be maximized. If it is assumed that $n$ available DMUs should be studied, and each of them has $m$ inputs and $s$ outputs, the efficiency of the $j$ th DMU will be computed by Equation 1:

$$
\begin{aligned}
& \text { Maximize } E_{0}=\sum_{r=1}^{s} u_{r} y_{r 0}, \\
& \text { s.t. } \\
& \sum_{i=1}^{m} v_{i} x_{i 0}=1, \\
& \sum_{r=1}^{s} u_{r} y_{r j}-\sum_{i=1}^{m} v_{i} x_{i j} \leq 0, \\
& u_{r} \geq 0, \quad r=1, \ldots, s, \\
& v_{i} \geq 0, \quad i=1, \ldots, m,
\end{aligned}
$$

where $u_{r}$ is the weight of output $r, v_{i}$ is the weight of input $i, y_{r j}$ is the value of output $r$ from DMU $j$, and $x_{i j}$ is the value of input $i$ from DMU $j$ and where $\mathrm{DMU}_{0}$ is the DMU under study.

In this paper, each treatment is considered as a DMU, each controllable factor is considered as an input variable and finally each response variable is considered as an output.

For using DEA in MRO problems, input variables should be STB type and response variables should be LTB type; however this condition does not necessarily hold in all processes. For this reason, before applying DEA, it should be checked that the controllable factors are STB type variables and the responses are LTB-type ones. 
Although there might be different types of responses in an MRO problem, since we used the Taguchi method, the responses are transformed into the $\mathrm{SN}$ ratio values using Equations 2, 3, and 4 and we know that the SN ratio is a LTB-type variable. For the controllable factors, according to their properties, we can assure that whether a controllable factor is STB type or not.

$$
x_{i j}=-10 \log _{10}\left[\frac{1}{l} \sum_{k=1}^{i} y_{i j k}^{2}\right] \quad 0 \leq y_{i j k} \leq \infty
$$

(for the smaller-the-better response)

$$
x_{i j}=-10 \log _{10}\left[\frac{1}{l} \sum_{k=1}^{i} \frac{1}{y_{i j k}^{2}}\right] \quad 0 \leq y_{i j k} \leq \infty
$$

(for the larger-the-better response)

$$
x_{i j}=10 \log _{10}\left[\frac{\bar{y}_{i j}^{2}}{S_{i j}^{2}}\right] \quad 0 \leq y_{i j k} \leq \infty
$$

(for the nominal-the-better response)

Let the SN ratio be $x_{i j}$ for the $j$ th response at the $i$ th trial, for $i=1, \ldots, m, j=1, \ldots, n . y_{i j k}$ is the observed data for the $j$ th response at the $i$ th trial, in the $k$ th repetition, $\bar{y}_{i j}=\frac{1}{l} \sum_{k=1}^{l} y_{i j k}$ (the average observed data for the $j$ th response at the $i$ th trial), $S_{i j}^{2}=\frac{1}{l-1} \sum_{k=1}^{l}\left(y_{i j k}-\bar{y}_{i j}\right)^{2}$ (the variation of the observed data for the $j$ th response at the $i$ th trial) for, $i=1, \ldots, m$ and $j=1, \ldots, n$ and $k=1, \ldots, l$. Now, $x_{i j}$ is normalized as $Z_{i j}\left(0 \leq Z_{i j} \leq 1\right)$ by Equation 5 to avoid the effect of adopting different units.

$$
Z_{i j}=\frac{X_{i j}-\min \left\{X_{i j}, j=1,2, \ldots, n\right\}}{\max \left\{X_{i j}, j=1,2, \ldots, n\right\}-\min \left\{X_{i j}, j=1,2, \ldots, n\right\}}
$$

At the end of this step, an efficiency value is computed for each treatment which represents that how well the input variables, controllable factors, have been minimized and how well the output variables, $\mathrm{SN}$ ratios of responses, have been maximized. The efficiency value is a measure ranging from 0 to 1 and sometimes more than one treatment would have the efficiency equal to 1 .

Table 1 Response definitions for the injection molding process example

\begin{tabular}{|c|c|c|c|}
\hline Row & Factors & Levels & Type \\
\hline A & $\begin{array}{c}\text { Injection pressure (percent of machine max } \\
\text { pressure) }\end{array}$ & 40,50 & STB \\
\hline$B$ & $\begin{array}{c}\text { Injection speed (percent of machine max } \\
\text { speed) }\end{array}$ & $55,60,65$ & STB \\
\hline C & $\begin{array}{c}\text { Holding Pressure1 (percent of machine max } \\
\text { pressure) }\end{array}$ & $40,45,50$ & STB \\
\hline D & $\begin{array}{c}\text { Holding Pressure1 (percent of machine max } \\
\text { pressure) }\end{array}$ & $75,80,85$ & STB \\
\hline$E$ & Holding pressure Time (seconds) & $6,8,10$ & STB \\
\hline $\mathrm{N}$ & Nuisance factors, injection machines & $550 \mathrm{~A}, 550 \mathrm{~B}$ & STB \\
\hline
\end{tabular}

\begin{tabular}{lccc}
\hline Response & Description & Specification limit $(\mathbf{m m})$ & Type \\
\hline$Y_{1}$ & The size of the upper side & $483.5+0.3$ & NTB \\
$Y_{2}$ & The size of the lower side & $483.6+0.3$ & NTB \\
\hline
\end{tabular}

Table 2 Factors and their levels for the injection molding process example

Use maximin weight model to choose among the efficient treatments

In DEA method, it is common that more than one DMU would be selected as the efficient one. For the determination of the most efficient DMU, another mathematical modeling should be done. The maximin weight model was presented by Wang et al. (2009) for ranking DEA efficient units. This model is solved for all of efficient DMUs, the model is represented in Equation 6.

$$
\begin{aligned}
& \text { Maximize } w \\
& \sum_{i=1}^{\text {s.t. }} v_{i}=1 \\
& \sum_{r=1}^{s} u_{r} \hat{y}_{r o}-\sum_{i=1}^{m} v_{i} \hat{x}_{i 0}=0, \\
& \sum_{r=1}^{s} u_{r} \hat{y}_{r j}-\sum_{i=1}^{m} v_{i} \hat{x}_{i j} \leq 0, \quad j=1, \ldots, n \\
& u_{r} \geq w, \quad r=1, \ldots, s \text {, } \\
& v_{i} \geq w, \quad i=1, \ldots, m \text {, }
\end{aligned}
$$

\begin{tabular}{|c|c|c|c|c|c|c|c|c|c|}
\hline \multirow[t]{2}{*}{ Run } & \multicolumn{5}{|c|}{$\mathrm{L}_{18}$} & \multicolumn{2}{|c|}{$Y_{1}$} & \multicolumn{2}{|c|}{$Y_{2}$} \\
\hline & $A$ & $B$ & $C$ & $D$ & $E$ & $N_{1}$ & $N_{2}$ & $N_{1}$ & $\mathrm{~N}_{2}$ \\
\hline & 40 & 55 & 40 & 75 & 6 & 483.36 & 483.32 & 483.96 & 483.98 \\
\hline 2 & 40 & 55 & 45 & 80 & 8 & 483.34 & 483.38 & 483.74 & 484.06 \\
\hline 17 & 50 & 65 & 45 & 75 & 10 & 483.4 & 483.42 & 483.84 & 484.14 \\
\hline 18 & 50 & 65 & 50 & 80 & 6 & 483.38 & 483.32 & 483.88 & 484.06 \\
\hline
\end{tabular}

where $w$ is the maximin weight that could keep $\mathrm{DMU}_{0}$ efficient, $\hat{x}_{i j}(i=1, \ldots, m ; j=1, \ldots, n)$ is the normalized input obtained using Equation 7.

Table 3 Summary of experimental results for injection molding process example 
Table 4 Algorithm and its parameters considered for training the neural network

\begin{tabular}{|c|c|c|c|c|c|c|c|c|}
\hline Training algorithm & $\begin{array}{l}\text { Maximum number } \\
\text { of epochs to train }\end{array}$ & $\begin{array}{c}\text { Performance } \\
\text { goal }\end{array}$ & $\begin{array}{c}\text { Maximum } \\
\text { validation } \\
\text { failures }\end{array}$ & $\begin{array}{c}\text { Minimum } \\
\text { performance } \\
\text { gradient }\end{array}$ & $\begin{array}{c}\text { Initial } \\
m u\end{array}$ & $\underline{m u}_{\text {factor }}$ decrease & $\begin{array}{l}m u \text { increase } \\
\text { factor }\end{array}$ & $\underset{m u}{\text { Maximum }}$ \\
\hline $\begin{array}{l}\text { Levenberg-Marquardt back } \\
\text { propagation }\end{array}$ & 100 & 0 & 5 & $1 e-10$ & 0.001 & 0.1 & 10 & $1 \mathrm{e} 10$ \\
\hline
\end{tabular}

$$
\hat{x}_{i j}=\frac{x_{i j}}{\sum_{j=1}^{n} x_{i j}}, i=1, \ldots, m ; j=1, \ldots, n
$$

If there would be $k$ efficient units, by solving maximin weight model represented in Equation 7 for each efficient unit, a group of maximin weights, $w_{i 1}^{*}, w_{i 2}^{*}, \ldots w_{i k}^{*}$, are obtained and the DMU with the largest value of $w$ is considered as the most efficient treatment.

\section{Illustrative example}

For verifying the applicability of the proposed method, a real case study of an injection molding process, in a TV and monitor production line, is conducted. In the case under study, two responses are of interest and the responses are the sizes of the upper side and the lower side of a cabinet front of a monitor. The specification limits of responses are represented in Table 1 . In this table, the response types are determined so that we would be able to choose among the formula of computing $\mathrm{SN}$ ratios from Equations 2, 3, and 4.

According to the initial experiments and also operational experiences, five controllable factors are screened to set up the experimental design. The description of each controllable factor and also their corresponding levels are illustrated in Table 2.

According to the information given in Table 2, the $\mathrm{L}_{18}$ Taguchi design is selected for design of experiments. Since two similar machines can be used for production of the mentioned part, two nuisance factors are considered.

As it can be easily seen in Table 2, the controllable factors are mainly from the type of injection pressure and injection speed or processing time. According to maintenance considerations of injection machines, a production process with less needed injection pressure and less needed injection speed would incur less erosion to the machines, so all pressure-related factors and speedrelated factors are STB type. Besides, as much as the required time for a process is shorter, the production rate would increase, so a shorter processing time is more desired. By considering these aspects, all the mentioned controllable factors can be considered as STB-type inputs. An efficient treatment is a setting in which not only the quality requirements are met, but also the abovementioned preferences of the operation are satisfied. Some of the $\mathrm{L}_{18}$ orthogonal Taguchi experimental design results are reported in Table 3.
Tune-effective parameters of ANN for estimation of responses In the training phase, factor level values and noise factor levels are considered as inputs and corresponding response values are considered as outputs of neural networks. As results, there are 36 data divided into three groups of training, testing, and validation data. An important point in choosing testing and training data is that considering one replicate as training and other replicate as a testing data causes erroneous judgment. In this study, the 5th, 10th, and 16th experiments in condition of the first noise factor and second noise factor are considered as testing and validation data, respectively, and others as the training data. The algorithm and its significant parameters considered for training the neural network are reported in Table 4. In the training phase of the ANN, the linear function is selected as the transfer function for the last layer and the tangent sigmoid is used for other layers. By considering the dimension of training data, axial points for designing of experiments by CCD is determined in Table 5. For more details of the tuning method, see Hsieh and Tong (2001).

By performing such an experiment, the optimal setting for the parameters of the neural network are determined as reported in Table 6 .

\section{Train the ANN using tuned parameters and estimate unpracticed treatments}

In this step, data are divided into testing, training, and validation data subsets as mentioned in the previous section, and finally, the training of ANN is conducted using the tuned parameters obtained from the previous step.

It should be noted that the initial conducted experiment whose results are reported in Table 3, just included 4 treatment results from the 18 practiced treatments,

Table 5 Parameters and their levels studied in experiments based on CCD design in ANN parameter tuning

\begin{tabular}{lcccccc}
\hline Factors & \multicolumn{2}{c}{$\begin{array}{c}\text { Cube } \\
\text { points }\end{array}$} & \multirow{2}{c}{$\begin{array}{c}\text { Central } \\
\text { point }\end{array}$} & $\begin{array}{c}\text { Axial } \\
\text { points }\end{array}$ \\
\cline { 2 - 3 } \cline { 5 - 7 } & Low & High & & & Low & High \\
\hline The number of neuron in first layer & 4 & 8 & 6 & 2 & 10 \\
$\begin{array}{l}\text { The number of neuron in second } \\
\text { layer }\end{array}$ & 1 & 3 & 2 & 0 & 4 \\
\hline
\end{tabular}


Table 6 Optimum values of effective parameters in performance of ANN

\begin{tabular}{lc}
\hline Parameter & Optimum value \\
\hline The number of neurons in first layer & 5 \\
The number of neurons in second layer & 3 \\
RMSE of test data & 14.32 \\
RMSE of validation data & 14.70 \\
\hline
\end{tabular}

while by using ANN, many other unpracticed treatments and corresponding results can be estimated in the current step. For this regard, new levels are defined between initial levels. These levels are shown in Table 7.

According to the levels defined in Table 7, there are $5^{4} \times 3=1,875$ possible treatments (because of the five levels for factors B, C, D, E, and three levels for factor A) which their responses can be estimated by the trained ANN. The responses of these factor level combinations are estimated using the trained neural network. The estimated responses for new defined treatments are reported in Table 8.

\section{Evaluate the efficiency of all treatments using DEA}

In this step, we assume each of the estimated treatments reported in Table 8 as a certain DMU. The SN ratios of estimated responses are computed and then normalized in each treatment using Equations 3 and 5. In this step, evaluation of the efficiency for each treatment can be conducted by solving Equation 1.

Matlab software (MathWorks, Inc., Natick, MA, USA) is used to solve 1,875 linear models to determine the efficiency of each treatment. Finally, the efficiency value for 12 of them is obtained as equal to 1 . In the next step, the most efficient treatment would be selected among these 12 treatments.

Table 7 Factors and their new defined levels for the injection molding process example

\begin{tabular}{lcc}
\hline Row & Factors & Levels \\
\hline A & $\begin{array}{c}\text { Injection pressure (percent of machine } \\
\text { max pressure) }\end{array}$ & $40,45,50$ \\
B & $\begin{array}{c}\text { Injection speed (percent of machine } \\
\text { max speed) }\end{array}$ & $55,57.5,60,62.5,65$ \\
C & Holding pressure 1 (percent of machine \\
max pressure) & $40,42.5,45,47.5,50$ \\
D & Holding pressure 1 (percent of machine & $75,77.5,80,82.5,85$ \\
& max pressure) & \\
E & Holding pressure time (seconds) & $6,7,8,9,10$ \\
$\mathrm{~N}$ & Nuisance factors, injection machines & $550 \mathrm{~A}, 550 \mathrm{~B}$ \\
\hline
\end{tabular}

Table 8 Estimated values by neural networks for actual experiments for the injection molding process example

\begin{tabular}{|c|c|c|c|c|c|c|c|c|c|}
\hline \multirow[t]{2}{*}{ Combination } & \multicolumn{4}{|c|}{$\mathrm{L}_{18}$} & \multicolumn{2}{|r|}{$Y_{1}$} & \multicolumn{3}{|c|}{$Y_{2}$} \\
\hline & $A$ & $B$ & $C$ & $\bar{D}$ & $E$ & $N_{1}$ & $N_{2}$ & $N_{1}$ & $\mathrm{~N}_{2}$ \\
\hline C1 & 40 & 55 & 40 & 75 & 6 & 483.36 & 483.34 & 483.95 & 484.02 \\
\hline $\mathrm{C} 2$ & 40 & 55 & 40 & 75 & 7 & 483.35 & 483.35 & 483.9 & 484.05 \\
\hline C1874 & 50 & 65 & 50 & 85 & 9 & 483.32 & 483.33 & 483.78 & 484.13 \\
\hline C1875 & 50 & 65 & 50 & 85 & 10 & 483.32 & 483.35 & 483.79 & 484.1 \\
\hline
\end{tabular}

Use maximin weight model to choose among the efficient parameter combinations

In this step, minimum weighted restriction is applied to determine the most efficient treatment among all. Efficient treatments and weights which are obtained by solving Equation 6 are illustrated in Table 9. As mentioned before, the treatment with maximum weight is selected as the most efficient solution of the case study. The most efficient treatment is obtained as $A=45 \%, B=55 \%$, $C=40 \%$, and $D=80 \%$ and $E=6$ s.

The combination and corresponding values with the most efficient treatment are denoted in italics. For verifying the obtained results, the real results of the most efficient treatment are performed for a batch of 30 parts and the most efficient and the extracted results are compared with previous experimented data. Results of the comparisons are illustrated in the Table 10, in which $\mathrm{SN}_{1}$ and $\mathrm{SN}_{2}$ are signal-to-noise ratios of the first and second responses, respectively. Note that the most efficient treatment result has been considered as the 19th

Table 9 The maximin calculated weight for efficient combinations

\begin{tabular}{lcccccc}
\hline Combination & $\boldsymbol{A}$ & $\boldsymbol{B}$ & $\boldsymbol{C}$ & $\boldsymbol{D}$ & $\boldsymbol{E}$ & $\boldsymbol{w}_{\boldsymbol{j}}$ \\
\hline C100 & 40 & 55 & 47.5 & 85 & 10 & 0.000507 \\
C530 & 40 & 65 & 42.5 & 75 & 10 & 0.000508 \\
C636 & 45 & 55 & 40 & 80 & 6 & 0.000508 \\
C675 & 45 & 55 & 42.5 & 85 & 10 & 0.000426 \\
C748 & 45 & 55 & 50 & 85 & 8 & 0.000494 \\
C1008 & 45 & 62.5 & 40 & 77.5 & 8 & 0.000502 \\
C1201 & 45 & 65 & 47.5 & 75 & 6 & 0.000508 \\
C1420 & 50 & 57.5 & 42.5 & 82.5 & 10 & 0.000477 \\
C1505 & 50 & 60 & 40 & 75 & 10 & 0.000485 \\
C1691 & 50 & 62.5 & 45 & 82.5 & 6 & 0.000077 \\
C1768 & 50 & 65 & 40 & 82.5 & 8 & 0.000487 \\
C1815 & 50 & 65 & 45 & 80 & 10 & 0.000505 \\
\hline
\end{tabular}

The combination and corresponding values with the most efficient treatment are denoted in italics. 
Table 10 Validating results

\begin{tabular}{|c|c|c|c|c|}
\hline \multirow[t]{2}{*}{ Run } & \multicolumn{2}{|c|}{ SN ratio of the results } & \multirow{2}{*}{$\begin{array}{l}\text { Relative } \\
\text { efficient }\end{array}$} & \multirow[t]{2}{*}{$w_{j}$} \\
\hline & $\mathrm{SN}_{1}$ & $\mathrm{SN}_{2}$ & & \\
\hline 1 & 84.6542 & 90.6861 & 0.94 & \\
\hline 2 & 84.6545 & 66.6024 & 0.63 & \\
\hline 3 & 84.6549 & 70.6859 & 0.67 & \\
\hline 4 & 76.6955 & 63.8360 & 0.00 & \\
\hline 5 & 81.1332 & 67.7633 & 0.35 & \\
\hline 6 & 81.1329 & 66.0764 & 0.33 & \\
\hline 7 & 90.6753 & 71.6012 & 1.00 & 0.0316 \\
\hline 8 & 84.6549 & 68.4083 & 0.57 & \\
\hline 9 & 84.6552 & 73.7852 & 0.68 & \\
\hline 10 & 78.6346 & 63.8382 & 0.15 & \\
\hline 11 & 90.6757 & 69.8589 & 1.00 & 0.0297 \\
\hline 12 & 81.1332 & 69.8579 & 0.37 & \\
\hline 13 & 90.6746 & 70.6848 & 1.00 & 0.0256 \\
\hline 14 & 84.6549 & 67.7630 & 0.57 & \\
\hline 15 & 81.1332 & 66.0764 & 0.32 & \\
\hline 16 & 84.6545 & 67.1635 & 0.57 & \\
\hline 17 & 90.6760 & 67.1646 & 1.00 & 0.0000 \\
\hline 18 & 81.1325 & 71.6012 & 0.39 & \\
\hline 19 & 83.5709 & 106.2443 & 1.00 & 0.0348 \\
\hline
\end{tabular}

The combination and corresponding values with the most efficient run and corresponding maximin weight is denoted in italics. run. At first, efficient treatments among these 19 treatments are determined, then the most efficient treatment is selected. As it is observed, in this stage, the previous most efficient treatment is selected as the most efficient one. It shows that the obtained treatment as the most efficient one is theoretically and practically the most possible efficient treatment.

For increasing the applicability of the final results, one-way and two-way sensitivity analyses of efficiency under different values of related factors have been studied. For this purpose, lots of experimented data is necessary to track the sensitive parameters; also, efficiency calculation requires lots of computations for the estimated response values. So, an artificial neural network is applied as the efficiency estimator of different treatments. For this purpose, an ANN is trained by using level values of 1,875 treatments as inputs and efficiency of them as outputs. Then, the sensitivity analysis is done under different values of controllable factors in one or two ways using the trained efficiency estimator neural network. Results of the sensitivity analyses are illustrated in Figure 3. It can be observed that controllable factors $A$ and $D$ can be changed in intervals of about (42 to 45 ) and (79 to 81 ), respectively, without changing the selected treatment efficiency score; however, factors $\mathrm{B}, \mathrm{C}$, and $\mathrm{E}$ have inverse relation to the efficiency score in the analyzed amplitude.

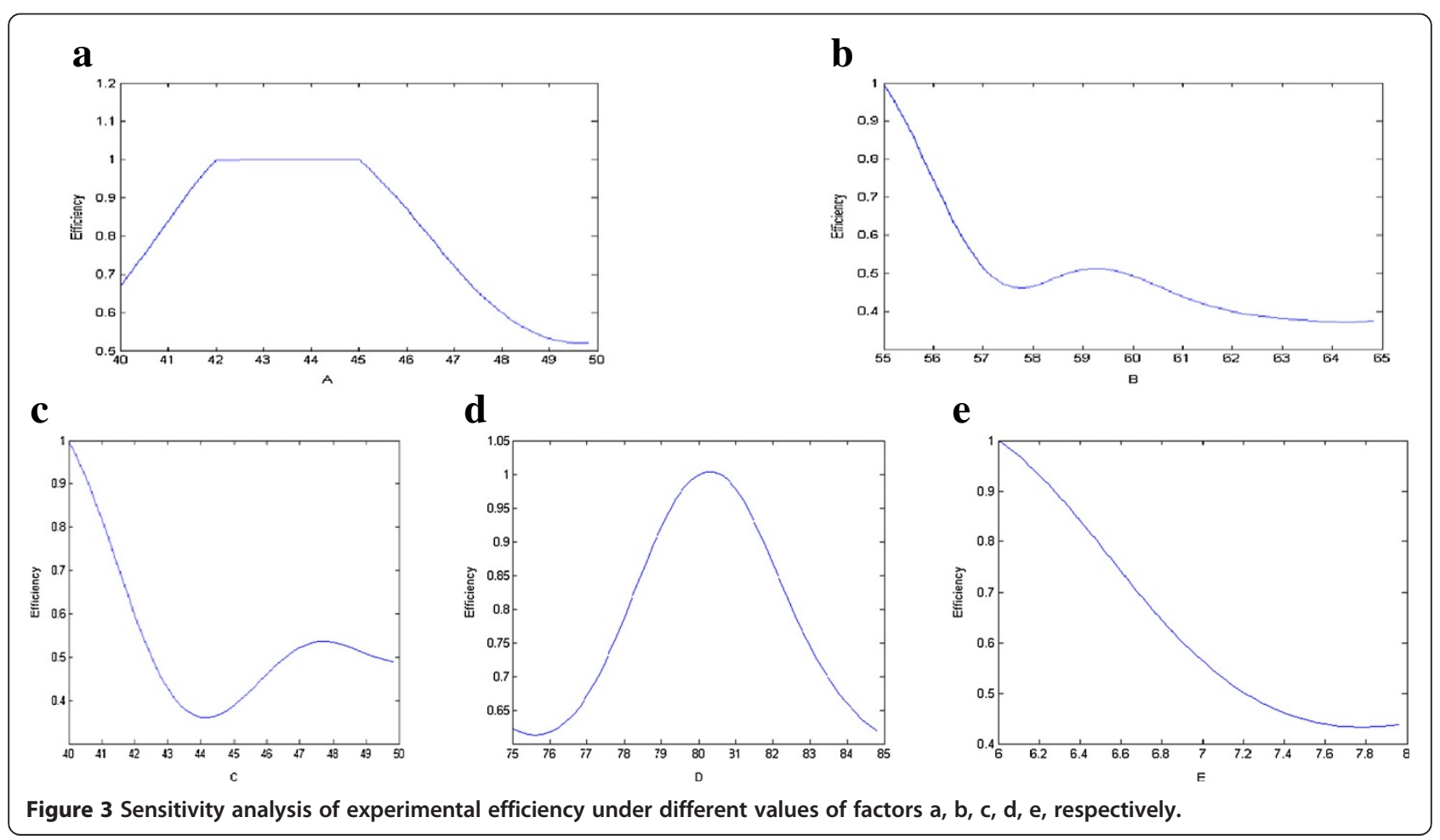




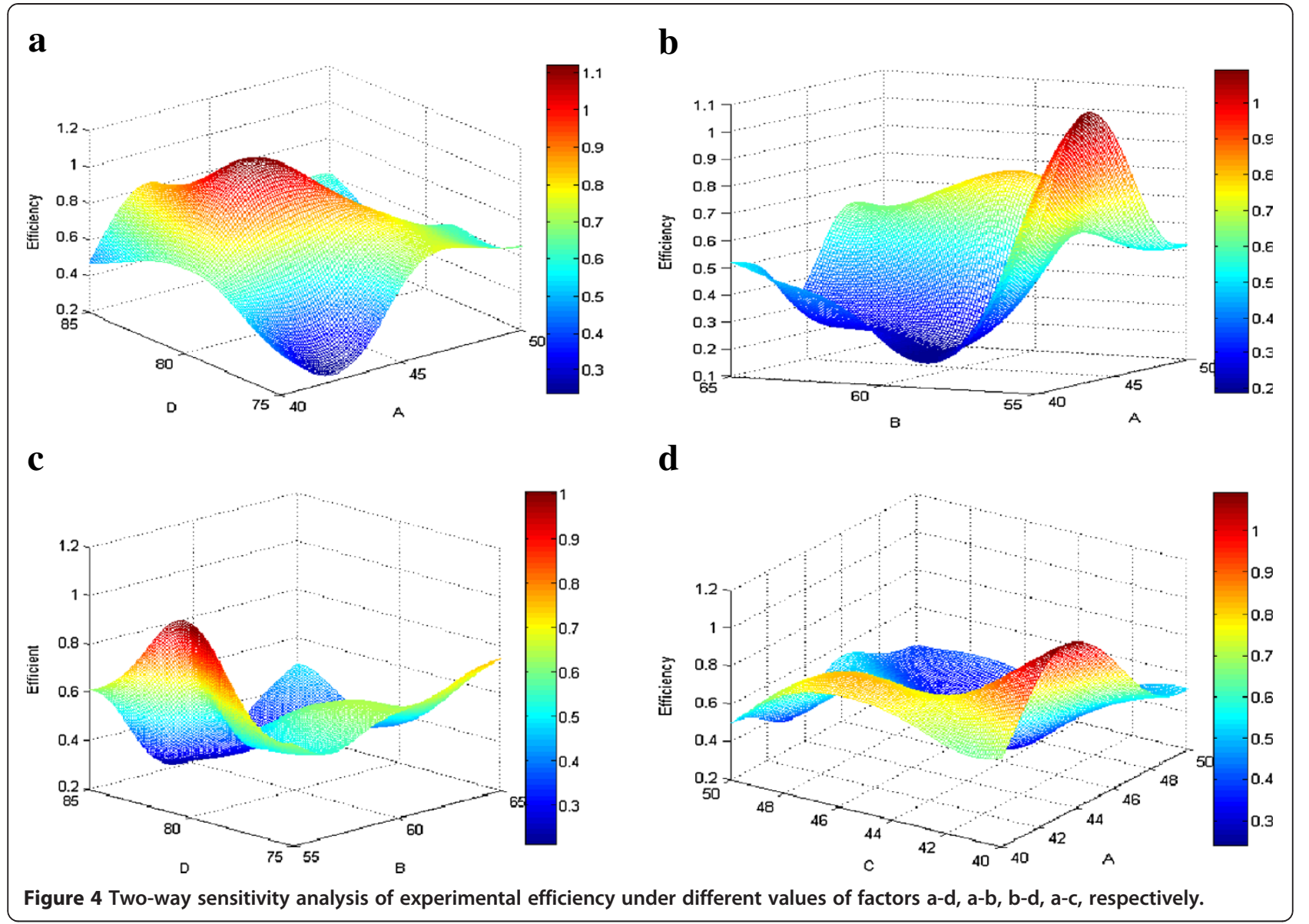

Two-way sensitivity analysis has been illustrated in Figure 4; it shows that there are interactions between any pairs of controllable factors which affect the efficiency score and that simultaneous analysis of controllable factors instead of individual analysis is more desirable. This verifies that the proposed efficiency analysis of treatments in multiple-response optimizations is a preferred technique than others especially when the controllable factors are as smaller-the-better type.

\section{Conclusions}

In this study, a four-step approach was presented to find the optimal treatment in multiple-response optimization problems. After conducting a Taguchi-designed experiment and collecting the response data, by using a tuned neural network, the responses of unpracticed treatments were estimated considering new levels defined for the controllable factors. Each treatment was assumed to be as a DMU and the smaller-the-better-type controllable factors were assumed as the input variables, whereas the computed $\mathrm{SN}$ ratios of responses were assumed to be as the outputs for the DEA modeling. Then data envelopment analysis was applied to obtain the efficiency of each treatment. Finally, the maximin weight model was applied to find the most efficient treatment.

In the proposed method, for assisting the economic aspects of the process improvement, the type of controllable factors was accounted for, and using this approach, the overall output quality of the process was maximized while the usage of input variables was minimized. For validation of the study, the proposed method was applied in a plastic molding process as a real case and the results were compared and analyzed. Sensitivity analysis of the efficiency deviation, which was the useful tool for analyzing results, was presented by applying another neural network. The analysis showed that the proposed approach was a proper tool in discrete multiple response optimization especially for the STB controllable factors. As illustrated in this paper, the proposed approach was based on the response values and it did not consider the variations of responses; so, using other approaches which consider the variation can be future studies of STB-type controllable factors in MRO problems. 


\section{Competing interests}

The authors declare that they have no competing interests.

\section{Authors' contributions}

MB managed the study, completed the main idea and was responsible for integrating and revising the manuscript. AFG developed the methodology of the proposed approach. Besides HM contributed in developing the methodology as well as verifying it in the case study. All authors read and approved the final manuscript.

\section{Acknowledgements}

The authors would like to acknowledge the management of Iran office machine industry plastic factory for contributing in the case study.

\section{Author details}

${ }^{1}$ Department of industrial Engineering, Faculty of Engineering, Shahed University, Khalij Fars Highway, Tehran P.O. BOX: 3319118651, Iran. ${ }^{2}$ Faculty of industrial engineering and systems, college of engineering, University of Tehran, Enghelab street, Tehran P.O. BOX: 11155-4563, Iran.

Received: 1 October 2012 Accepted: 17 October 2013 Published: 14 Nov 2013

\section{References}

Amiri A, Bashiri M, Mogouie H, Doroudynan MH (2012) Non-normal multiple response optimization using process capability index. Scientia Iranica 19(6):1894-1905

Bashiri M, Geranmayeh AF (2011) Tuning the parameters of an artificial neural network using central composite design and genetic algorithm. Scientia Iranica 18(6):1600-1608

Bashiri M, Moslemi A (2013) Simultaneous robust estimation of multi-response surfaces in the presence of outliers. Int J Ind Eng Int 9(7):2-12

Caporaletti LE, Dulá JH, Womer NK (1999) Performance evaluation based on multiple attributes with nonparametric frontiers. Omega 27:637-645

Chang H (2006) Dynamic multi-response experiments by backpropagation networks and desirability functions. J Chin Inst Ind Eng 23(4):280-288

Chang $\mathrm{H}$ (2008) A data mining approach to dynamic multiple responses in Taguchi experimental design. Expert Syst Appl 35(3):1095-1103

Chang H, Chen Y (2011) Neuro-genetic approach to optimize parameter design of dynamic multiresponse experiments. Appl Soft Comp 11:436-442

Charnes A, Cooper WW, Rhodes E (1978) Measuring the efficiency of decision making units. Eur J Oper Res 2(6):429-444

Desai K, Survase S, Saudagar P, Lele S, Singhal R (2008) Comparison of artificial neural network (ANN) and response surface methodology (RSM) in fermentation media optimization: case study of fermentative production of scleroglucan. Biochem Eng J 41(3):266-273

Erzurumlu T, Oktem H (2007) Comparison of response surface model with neural network in determining the surface quality of moulded parts. Mater Des 28(2):459-465

Gauri SK, Pal S (2010) Comparison of performances of five prospective approaches for the multi-response optimization. Int J Adv Manuf Technol 48(9):1205-1220

Goel T, Vaidyanathan R, Haftka TR, Shyy W, Queipo VN, Tucker K (2007) Response surface approximation of Pareto optimal front in multi-objective optimization. Comp Methods Appl Mech Eng 196(1):879-893

Gutierrez E, Lozano S (2010) Data envelopment analysis of multiple response experiments. Appl Math Model 34(5):1139-1148

Hesieh K, Tong L (2001) Optimization of multiple quality responses involving qualitative and quantitative characteristics in IC manufacturing using neural networks. Comp Ind 46(1):1-12

Hsu C (2001) Solving multi-response problems through neural networks and principal component analysis. J Chin Inst Ind Eng 18(5):47-54

Hsu C (2004) An integrated approach to enhance the optical. Int J Prod Econ 92(3):241-254

Khaw JF, Lim B, Lim LE (1995) Optimal design of neural networks using the Taguchi method. Neurocomputing 7(3):225-245

Kim Y, Yum B (2004) Robust design of multilayer feedforward neural networks: an experimental approach. Eng Appl Artificial Intell 17(3):249-263

Li T, Su C, Chiang T (2003) Applying robust multi-response quality engineering for parameter selection using a novel neural-genetic algorithm. Comp Ind 50(1):113-122
Liao H (2004) A data envelopment analysis method for optimizing multiresponse problem with censored data in the Taguchi method. Comp Ind Eng 46(4):817-835

Liao HC (2005) Using N-D method to solve multi-response problem in Taguchi. J Intell Manuf 16:331-347

Liao HC, Chen YK (2002) Optimizing multi-response problem in the Taguchi method by DEA based ranking method. Int J Qual Reliability Manage 19(7):825-837

Maghsoodloo S, Ozdemir G, Jordan V, Huang CH (2004) Strengths and limitations of Taguchi's contributions to quality, manufacturing, and process engineering. J Manuf Syst 23(2):73-126

Myers R, Montgomery D (2002) Response surface methodology: process and product optimization using designed experiments, 2nd edition. Wiley, New York

Namvar-AsI M, Soltanieh M, Rashidi A, Irandoukht A (2008) Modeling and preparation of activated carbon for methane storage I. Modeling of activated carbon characteristics with neural networks and response surface method. Energy Conv Manage 49(9):2471-2477

Niaki STA, Hoseinzade S (2013) Forecasting S\&P 500 index using artificial neural networks and design of experiments. J Indust Eng 9(1):1-9

Noorossana R, Davanloo Tajbakhsh S, Saghaei A (2009) An artificial neural network approach to multiple-response optimization. Int J Adv Manufact Technol 40(11):1227-1238

Ortiz F, Simpson J, Pignatiello J, Heredia-Langner A (2004) A genetic algorithm approach to multiple-response optimization. J Qual Technol 36:432-450

Ozcelik B, Erzurumlu T (2006) Comparison of the warpage optimization in the plastic injection molding using ANOVA, neural network model and genetic algorithm. J Mat Proces Technol 171(3):437-445

Packianather M, Drake P, Rowlands H (2000) Optimizing the parameters of multilayered feedforward neural networks through Taguchi design of experiments. Qual Reliability Eng Int 16(6):461-473

Peterson G, St Clair D, Aylward S, Bond WE (1995) Using Taguchi's method of experimental design to control errors in layered perceptrons. IEEE Transac Neural Networks 6(1):949-961

Robinson TJ, Borror CM, Myers RH (2004) Robust parameter design: a review. Qual Reliability Eng Int 20:81-101

Sibalija TV, Majstorovic VD (2012) An integrated simulated annealing-based method for robust multiresponse process optimisation. Int J Adv Manufact Technol 59:1227-1244

Sukthomya W, Tannock J (2005) The optimisation of neural network parameters using Taguchi's design of experiments approach: an application in manufacturing process modelling. Neural Comp Appl 14:337-344

Taguchi G, Chowdhury S (2000) Robust design engineering. McGraw-Hill, New York

Tbanassoulis E (2001) Introduction to the theory and application of data envelopment analysis. Kluwer, Norwell

Tortum A, Yayla N, Çelik C, Gökdağ M (2007) The investigation of model selection criteria in artificial neural networks by the Taguchi method. Physica A: Stat Mech Appl 386:446-468

Tsao C (2008) Comparison between response surface methodology and radial basis function network for core-center drill in drilling composite materials. Int J Adv Manufact Technol 37(11):1061-1068

Wang YM, Luo Y, Liang L (2009) Ranking decision making units by imposing a minimum weight restriction in the data envelopment analysis. J Comput Appl Math 223(1):469-484

Zang C, Friswell MI, Mottershead JE (2005) A review of robust optimal design and its application in dynamics. Comp Struct 83:315-326

\subsection{6/2251-712X-9-30}

Cite this article as: Bashiri et al:: A neuro-data envelopment analysis approach for optimization of uncorrelated multiple response problems with smaller the better type controllable factors. Journal of Industrial Engineering International 2013, 9:30 